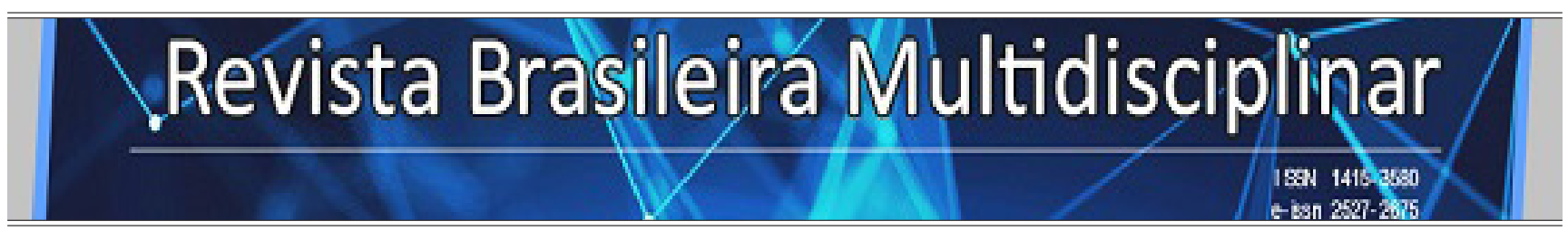

http://revistarebram.com/index.php/revistauniara

\title{
Perfil fitoquímico de extratos etanólicos e metanólicos do Croaton Blanchetianus
}

Antonia Isabelly Bezerra da Silva*; Geovan Figueirêdo de Sá-Filho ${ }^{* *}$; Lucidio Clebeson de Oliveira ${ }^{* * *}$; Fausto Pierdona

Guzen $^{* * *}$; José Rodolfo Lopes de Paiva Cavalcanti ${ }^{\star * *}$; Jeferson de Souza Cavalcante ${ }^{\star * * *}$.

${ }^{*}$ Bacharel em Biomedicina pela Faculdade Nova Esperança de Mossoró(FACENE/RN).

${ }_{*}^{*}$ Mestrado em Ecologia e Conservação pela Universidade Federal Rural do Semi-Árido UERN.

${ }_{* * *}$ Doutorado em Psicobiologia pela Universidade Federal do Rio Grande do Norte. UERN.

**** Doutorado em Ciências (Fisiologia Humana) pela Universidade de São Paulo.

*Autor para correspondência e-mail: isabellybezerra22@gmail.com

\section{Palavras-chave}

Marmeleiro

Fitoquímico

Metabólitos Secundários

\section{KEYWORDS}

Marmeleiro

Phytochemistry

Secodary Metabolites

\begin{abstract}
RESUMO
O Brasil é considerado o país com a maior biodiversidade do mundo e um dos seus biomas, a Caatinga, possui elevada heterogeneidade vegetacional e endemismo, o que torna esse ambiente de extrema importância biológica. Apesar de ser um bioma onde o estudo das plantas medicinais é bastante explorada, a Caatinga ainda possui muitas espécies de plantas que não foram devidamente analisadas, entre essas espécies existem o Croton blanchetianus, conhecido popularmente como marmeleiro ou marmeleiro-do-mato, com informações acerca de suas propriedades medicinas ainda com lacunas. Sendo assim, o objetivo desse estudo foi analisar a composição fitoquímica dos extratos etanólicos e metanólicos das folhas e raízes do Marmeleiro (Croton blanchetianus). A pesquisa foi de natureza qualitativa e de caráter experimental. A coleta da espécie foi no Sítio Chafariz, zona rural da cidade de Mossoró- $\mathrm{RN}$, onde foram coletadas as raízes e folhas da planta. Após a identificação da espécie foram aplicadas técnicas de farmacognosia e bioprospecção, para possibilitar a obtenção dos extratos, cujas análises fitoquímicas foram então realizadas. Por meio da triagem fitoquímica, pôde-se observar reações colorimétricas sugestivas de alcaloides, saponinas, quinonas e compostos fenólicos, especificamente, taninos e cumarinas. Não foi possível identificar flavonoides em nenhum dos extratos. Essas substâncias presentes nos extratos do marmeleiro, indicam uma possível presença de propriedades terapêuticas relativo à planta, sendo necessários estudos mais aprofundados sobre o Croton blanchetianus.
\end{abstract}

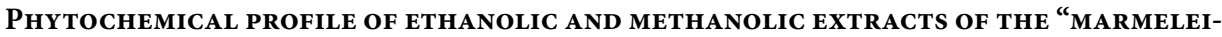 Ro" (CROton Blanchetianus)}

Brazil is considered the country with the greatest biodiversity in the world and one of its biomes, the Caatinga, has high vegetational heterogeneity and endemism, which makes this environment of extreme biological importance. Despite being a biome where the study of medicinal plants is widely explored, the Caatinga still has many species of plants that have not been properly analyzed, among these species there is Croton blanchetianus, popularly known as quince or quince, with information about its medicinal properties still with gaps. Thus, the objective of this study was to analyze the phytochemical composition of the ethanolic and methanolic extracts from the leaves and roots of the quince (Croton blanchetianus). The research was of a qualitative nature and of an experimental character. The species was collected at Sítio Chafariz, a rural area in the city of Mossoró-RN, where the plant's roots and leaves were collected. After the identification of the species, pharmacognosy and bioprospecting techniques were applied to make it possible to obtain the extracts, whose phytochemical analyzes were then performed. Through phytochemical screening, it was possible to observe colorimetric reactions suggestive of alkaloids, saponins, quinones and phenolic compounds, specifically, tannins and coumarins. It was not possible to identify flavonoids in any of the extracts. These substances present in the quince extracts indicate a possible presence of therapeutic properties relative to the plant, requiring further studies on Croton blanchetianus 


\section{INTRODUÇÃo}

O interesse em pesquisar propriedades medicinais de plantas para fins terapêuticos acompanha a história da humanidade, essas propriedades vêm sendo exploradas extensivamente pelos pesquisadores e pela indústria farmacêutica interessada em desenvolver novos medicamentos (CALIXTO E SIQUEIRA, 2008). A tradição do uso das plantas pela medicina popular, realizado mesmo sem o conhecimento químico das plantas, traz importantes informações terapêuticas acumuladas durante séculos (MACIEL 2002).

A Caatinga brasileira é um bioma bastante heterogêneo, principalmente em relação as espécies vegetais, possibilitando a população da região diversas possibilidades de plantas para utilizar em intervenções terapêuticas, em decorrência disso o interesse em se pesquisar plantas com potencial terapêutico neste bioma tem aumentado nos último anos (MMA, 2003; GUEDES, SAWAYA E NOGUEIRA, 2014). Os levantamentos etnobotânicos realizados na região mostram que as plantas da Caatinga são utilizadas pela comunidade para tratar diferentes enfermidades, entre elas: doenças de pele, respiratórias, gastrintestinais e infecções variadas (TROVÃO, 2007).

Mesmo com o número de estudos e publicações científicas sobre o potencial biológico de plantas da Caatinga terem crescido nos últimos anos (SÁ-FILHO, 2020), ainda existe uma extensa lacuna das plantas que são utilizadas para fins medicinas pela população que não foram submetidas a estudos científicos para confirmar sua eficácia no tratamento terapêutico (SILVA, 2015). A espécie vegetal Croton blanchetianus é um desses casos, conhecida popularmente como marmeleiro ou marmeleiro-do-mato e normalmente encontrada na região Nordeste, é utilizada na medicina popular (FRANCO; BARROS, 2006) para tratar diversas enfermidades como hemorragia uterina, hemoptise, dor de estômago, vômitos e diarreia (MATOS, 1999).

Os estudos fitoquímicos compreendem a extração e identificação dos constituintes presentes no vegetal, principalmente os metabólitos secundários que são os responsáveis por ações biológicas (SONAGLIO, 2010). A qualidade da extração dos metabólitos secundários é influenciada diretamente por diversos fatores, dentre eles o tipo de solvente utilizado (FERRO, 2008; NCUBE, AFOLAYAN E OKAN, 2011). O etanol apresenta caráter anfifílico, permitindo a extração tanto de substâncias com características apolares quanto polares (OLIVEIRA, 2016), já o metanol tem a capacidade de extrair uma maior quantidade de componentes (TIWARI, 2011).

\section{Oвjetivos}

O objetivo do presente trabalho foi analisar o rendimento e a presença dos metabólitos secundários nos extratos etanólicos e metanólicos da raiz e das folhas do marmeleiro (Croton blanchetianus) espécie nativa da Caatinga brasileira, bem como um apanhado geral sobre suas possíveis propriedades medicinais.

\section{MATERIAIs E MÉTODOS}

Seleção do material vegetal e preparação dos extratos

O marmeleiro (Croton blanchetianus) foi coletada no mês de julho de 2019 às 7h00, no "Sítio Chafariz" localizado na zona rural da cidade de Mossoró (5²7’55.1”S 37²1934.2”W). A espécie foi identificada pelos pesquisadores no local com o auxílio de um guia de plantas nativas da Caatinga (MAIA-SILVA, 2012), em seguida foram coletadas as raízes e folhas as quais foram separadas, lavadas, catalogadas e etiquetadas em sacos plásticos para o processamento em laboratório.

As partes do marmeleiro, devidamente acondicionados, foram submetidas ao método de determinação por dessecação(BORGES, 2005), EM ESTUFA A $35^{\circ} \mathrm{C}$ até atingir peso constante (aproximadamente 72 horas). Após o processo de secagem das partes das plantas, elas foram trituradas e reduzidas a partículas pequenas (35 milímetros) com auxílio de um moinho de facas tipo Willey SL-31 no laboratório de tecnologia da Madeira na Universidade Federal Rural do Semi-Árido (UFERSA). 


\section{Preparação dos extratos vegetais}

Com todas as partes da planta (raízes e folhas) reduzidas a pó foi possível iniciar o processo de obtenção dos extratos. Essa etapa foi realizada nos laboratórios de química e bioquímica da Faculdade Nova Esperança de Mossoró (FACENE/RN). Foi realizado o processo de maceração, utilizando como solventes o etanol (P.A.) e metanol (P.A.), onde a parte sólida do material foi pesada e submetida a maceração, durante 7 dias $(1: 10, \mathrm{p} / \mathrm{v})$. Posteriormente as soluções foram filtradas e levadas ao rotaevaporador (em média 5 minutos) para a retirada do solvente, e assim completar o processo de extração dos compostos vegetais. Em seguida os extratos ainda foram mantidos em banho maria $\left(50^{\circ} \mathrm{C}\right)$ para eliminação de possíveis resíduos dos solventes restantes nas amostras.

\section{RENDIMENTO DOS EXTRATOS}

Após a filtração, os rendimentos dos extratos foram calculados levando em consideração o peso do material inicial, esse peso foi padronizado em $10 \mathrm{~g}$, e o peso após rota evaporação. Calculou-se o rendimento de acordo com a fórmula:

$\operatorname{Re}=($ Pext /Pmaterial) $x 100$ (RODRIGUES, 2011).

Onde: $\mathrm{Re}=$ Rendimento total do extrato (\%); Pext= Peso do extrato seco (g) Pmaterial = Peso do material seco $(\mathrm{g})$.

\section{Triagem Fitoquímica}

A triagem fitoquimica foi realizada para obter a identificação qualitativa da presença dos metabólitos secundários pertencentes as classes dos fenóis, terpenóides, alcalóides, glicosídeos, sendo os seguintes compostos: Compostos Fenólicos, Taninos, Flavonoides, Cumarinas, Saponinas, Alcaloides e Quinonas. As metodologias utilizadas nesta etapa do experimento foram adaptadas dos seguintes autores: Costa (1994), Matos (1997), Brasil (2005), Harbone (1998), Simões (2004).

Para a identificação de compostos fenólicos foram realizadas duas metodologias, adição de cloreto férrico e adição de hidróxido de potássio. A presença de taninos foi observada através da reação ao adicionar gelatina nos extratos, já a busca por flavonoides foi feita por duas metodologias, a reação do cloreto férrico e cloreto de alumínio. A metodologia de saponinas é bem simples e rápida, apenas agita o tubo contendo o extrato e observa a formação ou não de espuma. A identificação de quinonas foi feita com hidróxido de potássio e ácido acético. Para identificar alcaloides foi usado o reagente de Wagner e Cumarinas foi por meio de luz ultravioleta.

\section{RESULTADOS E DISCUSSÃo \\ RENDIMENTO DOS EXTRATOS}

Após a obtenção dos extratos vegetais foi possível calcular os rendimentos dos processos de extração dos dois solventes. O rendimento do extrato etanólico da folha foi de 3,37\% sendo maior que o rendimento do extrato metanólico $(2,43 \%)$. O mesmo comportamento foi observado no extrato etanólico da raiz cujo rendimento foi de 4,96\%, maior que o rendimento do extrato metanolico (1,34\%) (Quadro 1). 
Quadro 1- Rendimento dos extratos etanólicos e metanólicos das folhas e raízes do Croton blanchetianus.

\begin{tabular}{|c|c|c|c|c|}
\hline Parte da espécie & $\begin{array}{c}\text { Solvente utili- } \\
\text { zado }\end{array}$ & Massa utilizada & Massa do extrato & Rendimento \\
\hline Folha & Etanol & $10 \mathrm{~g}$ & $0,337 \mathrm{~g}$ & $3,37 \%$ \\
\hline Folha & Metanol & $10 \mathrm{~g}$ & $0,243 \mathrm{~g}$ & $2,43 \%$ \\
\hline Raiz & Etanol & $10 \mathrm{~g}$ & $0,496 \mathrm{~g}$ & $4,96 \%$ \\
\hline Raiz & Metanol & $10 \mathrm{~g}$ & $0,134 \mathrm{~g}$ & $1,34 \%$ \\
\hline
\end{tabular}

Fonte: elaborado pelos autores.

Observou-se que o extrato etanólico da raiz obteve um maior rendimento comparado aos outros extratos. O extrato etanólico da folha teve rendimento semelhante em estudo realizado por Rodrigues (2017), onde foi investigado os rendimentos dos extratos etanólicos das folhas de duas espécies de Croton. Não foram encontrados estudos na literatura com extratos metanólicos de espécies de Croton para uma possível comparação dos resultados. Além disso, provavelmente pode existir algum metabólito secundário em maior quantidade no Croton blanchetianus do presente estudo, que possui maior afinidade para ser extraído pelo etanol, justificando o motivo do rendimento maior do etanol em comparação com o metanol.

Análise fitoquímica dos extratos

A análise qualitativa dos extratos metanólicos e etanólicos das raízes e folhas do Croton Blanchetianus possibilitou a percepção da presença de diferentes classes de compostos (Tabela 2).

Tabela 2 - Perfil fitoquímico nos extratos etanólicos e metanólicos das folhas e raízes do Croton Blanchetianus.

\begin{tabular}{l|l|l|l|l}
\hline & $\begin{array}{l}\text { EXTRATO } \\
\text { ETANOLICO DA } \\
\text { FOLHA }\end{array}$ & $\begin{array}{l}\text { EXTRATO } \\
\text { METANOLICO DA } \\
\text { FOLHA }\end{array}$ & $\begin{array}{l}\text { EXTRATO } \\
\text { ETANOLICO DA } \\
\text { RAIZ }\end{array}$ & $\begin{array}{l}\text { EXTRATO } \\
\text { METANOLICO } \\
\text { DA RAIZ }\end{array}$ \\
\hline $\begin{array}{l}\text { COMPOSTOS } \\
\text { FENOLICOS }\end{array}$ & + & + & + & + \\
\hline TANINOS & + & + & + & + \\
\hline FLAVONOIDES & - & - & - & - \\
\hline SAPONINAS & - & + & - & - \\
\hline QUINONAS & + & + & - & - \\
\hline ALCALOIDES & + & - & - & - \\
\hline CUMARINAS & + & - & - & - \\
\hline
\end{tabular}

(+): Presença; (-): Ausência.

Fonte: elaborado pelos autores.

No extrato etanolico da folha foi identificado compostos fenólicos, taninos, quinonas, alcaloides e cumarinas (Tabela 2). Além de ter tido um bom rendimento, o extrato etanolico da folha foi o que mais apresentou metabólitos secundários. Corroborando com o presente estudo Aquino (2017), relatou a presença de taninos nos extratos etanólicos da folha do Croton blanchetianus, e com relação aos alcaloides a literatura afirma que o Croton blanchetianus é fonte de alcaloides isoquinolínicos, sugerindo que a espécie 
também pode biossintetizar outras classes de alcaloides (FELIPE, ALMEIDA E GIORDADI, 2011).

As quinonas identificadas nos extratos etanolicos e metanolicos das folhas não há relatos na literatura sobre pesquisas cientificas com presença dessa classe em plantas do gênero Croton. Porém, diferentemente do extrato etanolico, no extrato metanolico da folha foi possível identificar saponinas. As saponinas são substâncias derivadas do metabolismo secundário das plantas que estão relacionadas, principalmente, com o sistema de defesa e são encontradas nos tecidos que são mais vulneráveis ao ataque fúngico, bacteriano ou predatório dos insetos (WINA, MUETZEL E BECKER, 2005), que seriam as folhas. Além disso, alguns estudos apontam que o metanol é um dos solventes indicados para extrair as saponinas (TIWARI, 2011;COWAN, 1999), corroborando com os resultados do presente estudo, onde as saponinas foram identificadas apenas no extrato metanólico das folhas.

Nos extratos etanolicos e metanolicos das raízes foi possível extrair apenas compostos fenólicos e taninos, além disso a presença de compostos fenólicos e taninos foi registrada nas diferentes partes da planta, mesmo com utilização de diferentes solventes (Tabela 2). Por se tratar de uma metodologia com reações colorimétricas, foi possível observar que nos extratos metanolicos a cor estava mais intensa, enquanto a coloração do extratos etanolicos estava mais densa (Figuras 1 e 2).

Figura 1- Análise colorimétrica dos compostos fenólicos nos extratos etanolicos (A) e metanolicos (B) das folhas do Croton blanchetianus.

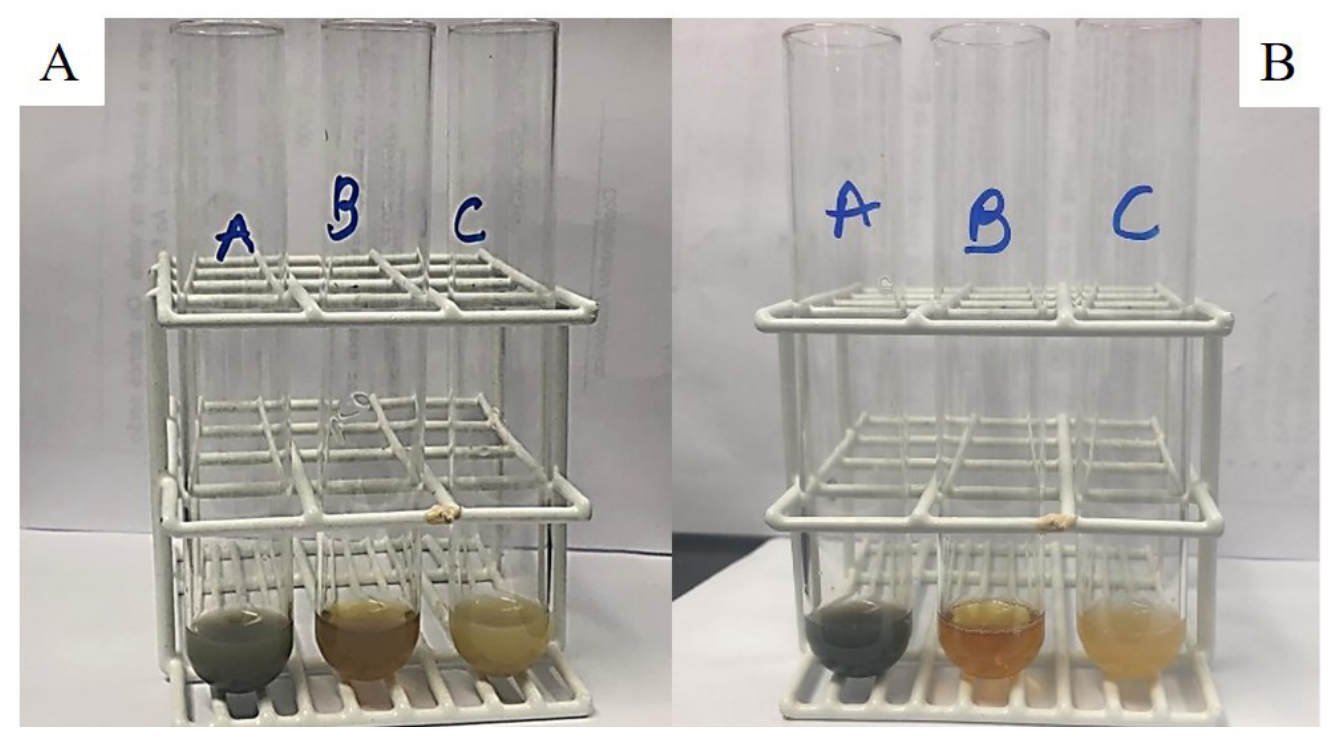

*Tubo A: Adição de Cloreto Férrico;

Tubo B: Adição de hidróxido de potássio

Tubo C: Controle da coloração inicial do extrato.

Fonte: Da autora (2019). 
Figura 2 - Análise colorimétrica de compostos fenólicos nos extratos etanolicos (A) e metanolicos (B) da raiz do Croton blanchetianus.

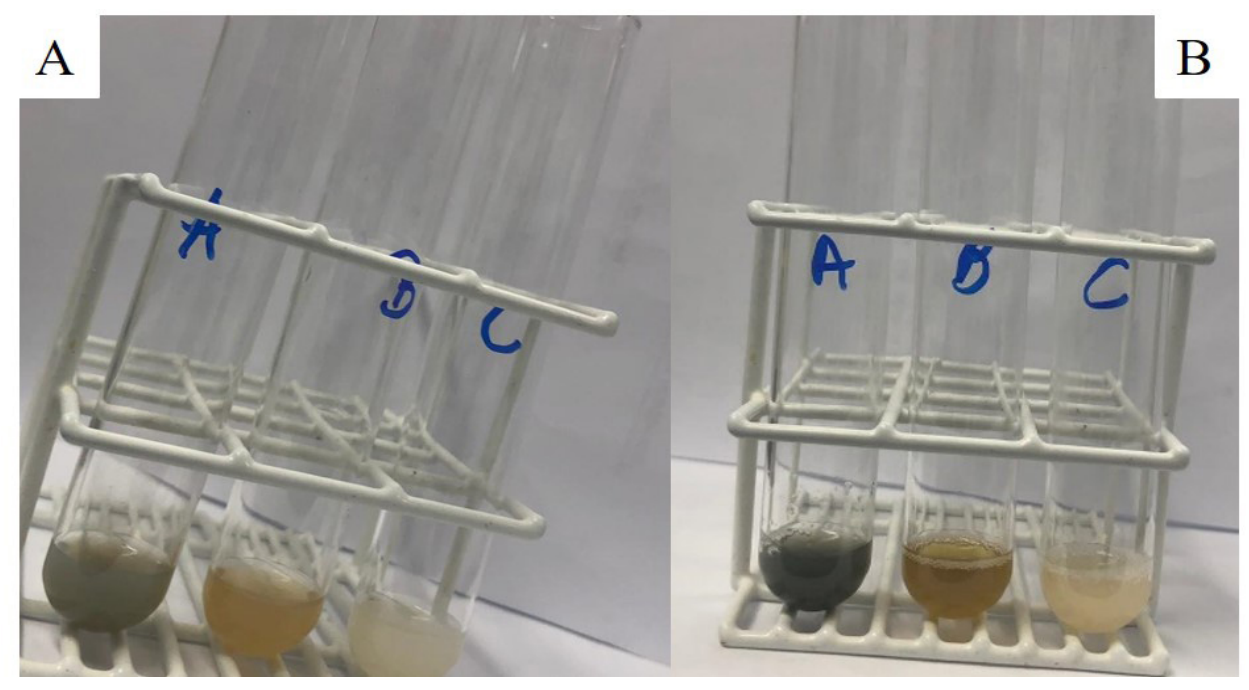

*Tubo A: Adição de Cloreto Férrico;

Tubo B: Adição de hidróxido de potássio

Tubo C: Controle da coloração inicial do extrato.

Fonte: Da autora (2019).

Segundo Simões, (2010) a utilização do metanol na fase de extração de drogas vegetais é considerado um dos mais eficientes em relação a extração dos compostos fenólicos. Os resultados encontrados no presente estudo, onde indica a presença de compostos fenólicos nas folhas e raiz pode sugerir que os extratos metanólicos ficaram com cores mais intensas por ter sido mais eficiente na extração dos compostos fenólicos.

Apesar de ser um composto que já descrito em diversas plantas e em espécie de Croton na Caatinga (AQUINO, 2017), no presente estudo não foi possível identificar a presença de flavonoides em nenhuma das partes do marmeleiro. A diferença encontrada nas composições químicas dos estudos qualitativos é atribuída a várias características inerentes a planta e a condições que ela está (relacionada à fisiologia, ao estágio de desenvolvimento, as condições ambientais, como a salinidade, o solo, umidade e temperatura, além da época que foi realizada a coleta) (SANGWAN, 2001). Além dessas interferências os resultados negativos no presente estudo não implicam em sua ausência total destes compostos, possivelmente o nível mínimo de detecção estejam abaixo para os testes qualitativos avaliados (BRUM et al., 2011).

Sobre o potencial terapêutico do Croton blanchetianus, Santos et al., (2005), verificaram que a partir do óleo essencial das folhas foi possível obter uma atividade analgésica. Além disso, efeitos broncodilatadores para o tratamento da asma foram observados por Pinho et al., (2010), porém ainda são escassas as comprovações cientificas acerca do potencial terapêutico dessa espécie. O uso do marmeleiro é feito apenas pelo conhecimento popular, na medicina popular é utilizado via oral, para inchaço (FRANCO ; BARROS, 2006), e também pode ser utilizado para hemorragia uterina, hemoptise, dor de estômago, vômitos e diarreia (MATOS, 1999).

Além das propriedades já descritas, os metabólitos identificados nesse estudo com o Croton blanchetianus sugerem atividade farmacológica decorrente da ação dos alcaloides no sistema nervoso, a nível do sistema nervoso central podem exercer ação depressora (morfina, escopolamina) ou estimulante (esticnina, codeína). Suas atividades fisiológicas e psicológicas ocorrem devido a sua interação com 
neurotransmissores. Em altas concentrações são tóxicos, porém em baixas concentrações agem como relaxantes musculares, tranquilizantes e analgésicos (GARCÍA; CARRIL, 2009).

\section{Conclusão}

O rendimento dos extratos etanolicos do Croton Blanchetianus foi superior aos extratos metanolicos. Além disso, o marmeleiro apresentou composição fitoquimica diferente em suas partes (Raiz e Folhas), com exceção da presença dos compostos fenólicos e dos taninos, que foi identificado em ambos. Isso sugere que as partes da planta do C. Blanchetianus pode ser base para o desenvolvimento de novos medicamentos, se for realizado os devidos estudos de suas potencialidades terapêuticas.

\section{REFERÊNCIAS}

AQUINO, V. V. F.; COSTA, J. G. M.; ANGÉLICO, E. C.; MEDEIROS, R. S.; LUCENA, M. F.A. Metabólitos secundários e ação antioxidante de Croton heliotripifolius e Croton blanchetianus. Acta Brasiliensis, v.1, n.3, p. 28-31, 2017.

BORGES, D. B.; FARIAS, M. R.; SIMÕES, C. M. O.; SCHENKEL, E. P. Comparação das metodologias da Farmacopéia Brasileira para determinação de água em matérias-primas vegetais, e validação da determinação de água em analisador de umidade para Calendula officinalis L., Foeniculum vulgare Miller, Maytenus ilicifolia Mart. ex. Reissek e Passiflora alata Curtis. Revista Brasileira de Farmacognosia. v. 15, n. 3, p. 229-236, 2005.

BRASIL, Farmacopeia Brasileira. 4. ed. São Paulo: Atheneu, 2005.

BRUM, T. F; ZADRA, M.; FROEDER, A.L.F; BOLIGON, A.A.; FROHLICH, J.K.; ATHAYDE, M.L. Análise fitoquímica preliminar das folhas de Vitex megapotamica (Sprengel) Moldenke. Revista Saúde, Santa Maria, v. 37, n. 2, p. 2011.

CALIXTO, J. G.; SIQUEIRA JUNIOR, J. M. Desenvolvimento de Medicamentos no Brasil: Desafios. Gazeta Médica da Bahia. v. 78, n. 1, p. 98-106, 2008.

COSTA, A .F. Farmacognosia, 5. Ed. Lisboa: Fundação Calouste Gulbenkian, v.3, 1994.

COWAN, M. M. Plant products as antimicrobial agents. Clinical microbiology reviews, v. 12, n. 4, p.564-582, 1999.

DA SILVA, N. L. A.; MIRANDA, F. A. A.; DA CONCEIÇÃO, G. M. Triagem Fitoquímica de Plantas de Cerrado, da Área de Proteção Ambiental Municipal do Inhamum, Caxias, Maranhão. Scientia Plena, v. 6, n. 2, p. 1-17, 2010.

FELIPE, A. K. F.; ALMEIDA, M. V.; GIORDANI, R. B. 2. Análise dos alcaloides de Croton blanchetianus Bail. 37a Reunião anual da Sociedade Brasileira de Química, 2014.

FERRO, Degmar. 2008. Fitoterapia: conceitos clínicos. Atheneu.

FRANCO, E.A.P.; BARROS, F.R.M. Uso e diversidade de plantas medicinais no Quilombo Olho D’água 
dos Pires, Esperantina, Piauí. Revista Brasileira de Plantas Medicinais. v. 8, n.3, p. 78-88, 2006.

GARCÍA, A. Á.; CARRIL, E.P. Metabolismo secundário de plantas. Reduca(Biologia) Serie Fisiologia vegetal, v.2, n. 6, p. 119-145, 2009.

GUEDES, T. B.; SAWAYA, R. J.; NOGUEIRA, C. Biogeography, vicariance and conservation of snakes of the neglected and endangered Caatinga region, north-eastern Brazil. Journal of Biogeography, v.41,n. 5,p. 919-931, 2014.

HARBORE, J.B. Phytochemial methods: a guide to modern techniques of plan analysis. Chapman and Hall. 3a edição, 1998.

SILVA, L. P.; MAIA, P. V. M.; NASCIMENTO, G. T. M.; CRUZ, J. S.; MORAIS, S. M.; SOUZA, A.N.C.; LAHLOU, S.; CARDOSO, J.H.L. Croton sonderianus essential oil samples distinctly affect rat airway smooth muscle. Phytomedicine, v. 17 p. 721-725, 2010.

MACIEL, M. A. M.; PINTO, A.C.; VEIGA JÚNIOR, V.F. Plantas Medicinais, a necessidade de estudos multidisciplinares. Quimica Nova, v. 25, p. 429-438, 2002.

MAIA-SILVA, C., SILVA, C. D., HRNCIR, M., QUEIROZ, R. D., \& IMPERATRIZ-FONSECA, V. L. 2012. Guia de plantas visitadas por abelhas na Caatinga. Fortaleza: Fundação Brasil Cidadão, 192-194.

MATOS, F. J. de A. Introdução à fitoquímica experimental. (2a. ed.) Fortaleza: EUFC, 1997.

MATOS, F.J.A. 1999. Plantas da medicina popular do Nordeste: propriedades atribuídas e confirmadas. Fortaleza: EDUFC.

MMA (Ministério do Meio Ambiente). Biodiversidade da Caatinga: áreas e ações prioritárias para conservação. Secretaria de Biodiversidade e Florestas. MMA, Brasília, 2004.

MOUCO, G.; BERNARDINO, M.J.; CORNELIO, M.L. Controle de qualidade de ervas medicinais. Revista biotecnologia Ciência e Desenvolvimento, v. 31, p. 68-73, 2003.

NCUBE, N.S.; AFOLAYAN, A.J.; OKOH, A.I. Assessment techniques of antimicrobial properties of natura compounds of plant origin: current methods and future trends. African Journal of Biotechnology, v.7, n.12, p.1797-1806, 2008.

OLIVEIRA, V.B, ZUCHETTO, M.; OLIVEIRA, C.F.; PAULA, C.S.; DUARTE, A.F.S.; MIGUEL, M.D.; MIGUEL, O.G. Efeito de diferentes técnicas extrativas no rendimento, atividade antioxidante, doseamentos totais e no perfil por CLAE-DAD de Dicksonia sellowiana (presl.). Hook, dicksoniaceae. Revista Brasileira de Plantas Medicinais, v.18, n.1, p. 230-239, 2016.

RODRIGUES, O.G.; ANGÉLICO, E. C.; COSTA, J. G. M.; LUCENA, M. F. A.; QUEIROGA-NETO, V.; SILVA, W. W. Avaliação da atividade antioxidante dos extratos botânicos de Croton Heliotrpiifolius Kunth. e Croton blanchetianus Baill: Resultados Preliminares. Agropecuária Científica no Semiárido, v.12, n.3, p.237-241, 2017. 
Silva et al.

RODRIGUES, T. S.; GUIMARÃES, S. F.; RODRIGUES, R. G.; GABRIEL, J. V. Métodos de secagem e rendimento dos extratos de folhas de Plectranthus barbatus (boldo-da-terra) e P. ornatos (boldo-miúdo). Revista Brasileira de Plantas Medicinais, v. 13, n. 1, p. 587-590, 2011.

SÁ-FILHO, G. F.; SILVA, A. I. B.; OLIVEIRA, L. C.; GUZEN, F. P.; CAVALCANTI, J. R. L. P.; CAVALCANTE, J. S. (Submetido) LEVANTAMENTO DA PRESENÇA DE POTENCIAL ANTI-INFLAMATÓRIO EM PLANTAS NATIVAS DA CAATINGA BRASILEIRA. The Brazilian Journal of Development (BJD), v. 5, No 10 (2019).

SANTOS, F. A.; JEFERSON, F. A.; SANTOS, C.C.; SILVEIRA, E.R.; RAO, V.S. R. Antinociceptive effect of leaf essential oil from Croton sonderianus in mice. Life Sci, v.77, n.23, p. 2953-2963, 2005.

SILVA, L. N.; TRENTIN, D. S.; ZIMMER, K. R.; TRETER, J.; BRANDELLI, C. L. C.; FRASSON, A. P.; TASCA, T.; SILVA, A. G.; SILVA, M. V.; MACEDO, A. J. Anti-infective effects of Brazilian Caatinga plants against pathogenic bacterial biofilm formation. Pharmaceutical Biology, v. 53, n. 3, p. 464-468, 2015.

SIMÕES, C.M.O. Farmacognosia: da planta ao medicamento. 6 $6^{\mathrm{a}}$ ed. Porto Alegre: UFRGS Ed. 2010. ISBN: 978-85-7025-927-1

SIMÕES, C.M.O.; SCHENKEL, E.P.; GOSMANN, G.; MELLO J.C.P.; MENTZ, L.A.; PETROVICK, P.R. Farmacognosia: da planta ao medicamento. 5. ed. Porto Alegre 2004.

SONAGLIO, D.; ORTEGA, G.G.; PETROVICK, P.R.; BASSANI, V.L. Desenvolvimento tecnológico e produção de fitoterápicos. In: SIMÕES, C.M.O.; SCHENKEL, E.P.; GOSMANN, G.; MELLO, J.C.P.; MENTZ, L.A.; PETROVICK, P.R. (org.) Farmacognosia: da planta ao medicamento. 5. ed. rev. e ampl., Porto Alegre: UFRGS, Florianópolis: UFSC, 2003. cap. 13, p. 289-32.

TIWARI, P.; KUMAR, B.; KAUR, M.; KAUR, G.; KAUR, H. Phytochemical screening and extraction: a review. Intern Pharm Science, v.1, n.1, p. 98-106, 2011.

TROVÃO, D.M.; FERNANDES, P.D.; ANDRANDE, L.A.; NETO., J.D. Variações sazonais de aspectos fisiológicos de espécies da Caatinga. Revista Brasileira de Engenharia Agricola Ambiental, v. 11, n. 3, p. 307-311, 2007.

WINA, E.; MUETZEL, S.; BECKER, K. The Impact of Saponins or Saponin Containing Plant Materials on Ruminant Production - A Review. Journal of Agricultural and Food Chemistry, v.53, n.21, p. 8093-8105, 2005. 